\title{
PELAKSANAAN PRINSIP KEHATI-HATIAN DALAM PEMBERIAN KREDIT KONSUMTIF PADA BANK NAGARI CABANG SITEBA
}

\author{
Misa Nora Andani, Ratna Widayati \\ Akademi Keuangan dan Perbankan Padang \\ ratnawidayati@akbpstie.ac.id
}

\begin{abstract}
ABSTRAK
Pasal 29 ayat (2) dalam UU Perbankan menyatakan bahwa " Bank wajib untuk memelihara tingkat kesehatan bank sesuai dengan ketentuan aspek kecukupan modal, kualitas aset, kualitas manajemen, likuiditas, rentabilitas, solvabilitas, dan aspek lain yang berhubungan dengan usaha bank, dan wajib melakukan kegiatan usaha sesuai dengan prinsip kehati-hatian". Berdasarkan ketentuan tersebut maka tidak ada alasan apapun bagi pihak bank untuk tidak melaksanakan prinsip kehatihatian dalam menjalankan usahanya. Tujuan penelitian ini adalah untuk menjelaskan bagaimana pelaksanaan prinsip kehati-hatian dalam pemberian kredit konsumtif pada Bank Nagari Cabang Siteba. Untuk memperoleh data dalam tugas akhir ini dilakukan penelitian kepustakaan dan penelitian lapangan. Penelitian kepustakaan yang digunakan untuk memperoleh data sekunder yang bersifat teoritis sedangkan penelitian lapangan dilakukan guna memperoleh data primer melalui wawancara. Dari hasil penelitian diketahui bahwa pelaksanaan prinsip kehati-hatian dalam pemberian kredit konsumtif pada Bank Nagari Cabang Siteba dapat dilihat dalam beberapa proses tahapan mulai dari permohonan kredit sampai dengan realisasi kredit dan dilanjutkan dengan pengawasan kredit. Hambatan yang dihadapi oleh Bank Nagari Cabang Siteba dalam pemberian kredit konsumtif adalah hambatan eksternal. Upaya yang dilakukan oleh Bank Nagari Cabang Siteba untuk mengatasi hambatan tersebut adalah dengan melakukan peringatan dini, melakukan penagihan langsung kepada nasabah debitur, melakukan rescheduling, reconditioning, restructuring, asuransi kredit, dan yang terakhir yaitu pelelangan agunan. Disarankan dalam menyalurkan kredit konsumtif pihak Bank Nagari Cabang Siteba agar lebih meningkatkan pada pengawasan kredit mulai dari kredit direalisasikan sampai dengan kredit lunas. Tujuannya agar terhindar dari kredit bermasalah.
\end{abstract}

Kata kunci : Pemberian Kredit dan Prinsip Kehati-hatian

\section{PENDAHULUAN}

Setiap negara berkepentingan dan menaruh perhatian yang besar terhadap fungsi dan peran pengawasan bank yang harus dilakukan oleh pemerintah. Sebab, bank sebagai lembaga kepercayaan memiliki karakter yang unik dibandingkan jenis usaha lain. Tujuan inti dari pengawasan bank adalah melindungi kepentingan masyarakat penyimpan yang mempercayakan dananya pada bank untuk memperoleh pembayaran kembali dan 
manfaatnya dari bank sesuai dengan sifat, jenis, dan cara pembayaran yang telah dijanjikan. Tujuan tersebut dapat dicapai, bila bank melakukan kegiatan usahanya berdasarkan atas usaha bank yang sehat dan dapat dipertanggung jawabkan.

Pengertian Bank sesuai dengan pasal 1 ayat (2) Undang-Undang Nomor 10 tahun 1998 tentang perbankan adalah badan usaha yang menghimpun dana dari masyarakat dalam bentuk simpanan dan menyalurkan dana kepada masyarakat dalam bentuk kredit dan atau bentuk-bentuk lainnya dalam rangka meningkatkan taraf hidup rakyat banyak.

Definisi kredit dalam pasal 1 angka 11 UU Perbankan adalah penyediaan uang atau tagihan yang dapat dipersamakan dengan itu, berdasarkan persetujuan atau kesepakatan pinjam-meninjam antara bank dengan pihak lain yang mewajibkan pihak peminjam untuk melunasi hutangnya setelah jangka waktu tertentu dengan pemberian bunga.

Pemberian kredit merupakan kegiatan utama bank, namun mengandung resiko yang adapat berpengaruh pada kesehatan dan kelangsungan usaha bank. Resiko kredit adalah resiko akibat kegagalan debitur dan/atau pihak lain dalam memenuhi kewajiban kepada bank. Untuk meminimalisir resiko dalam pemberian kredit, bank dalam melaksanakan usahanya harus menerapkan ketentuan perkreditan yang sehat.

Pasal 29 ayat (2) dalam UU Perbankan menyatakan bahwa " Bank wajib untuk memelihara tingkat kesehatan bank sesuai dengan ketentuan aspek kecukupan modal, kualitas aset, kualitas manajemen, likuiditas, rentabilitas, solvabilitas, dan aspek lain yang berhubungan dengan usaha bank, dan wajib melakukan kegiatan usaha sesuai dengan prinsip kehati-hatian". Berdasarkan ketentuan tersebut maka tidak ada alasan apapun bagi pihak bank untuk tidak menerapakan prinsip kehati-hatian dalam menjalankan usahanya.

Prinsip kehati-hatian (prudential principle) merupakan prinsip yang menyatakan bahwa lembaga keuangan dalam menjalan fungsi dan kegiatan usahanya wajib menerapkan prinsip kehati-hatian dengan mengenal customer dalam rangka melindungi dana masyarakat yang dipercayakan kepadanya.

Bank Nagari Cabang Siteba juga menyediakan beragam jenis kredit, salah satunya adalah kredit konsumtif. Kredit konsumtif adalah salah satu jasa yang diberikan bank dalam bentuk kredit yang ditujukan untuk membiayai kebutuhan nasabah terutama yang berhubungan dengan kegiatan konsumsi, misalnya: pembelian motor, mobil, dan barang elektronik yang bertujuan untuk pemakaian pribadi. Kredit konsumtif memiliki bunga yang relatif tinggi dibanding kredit investasi dan modal kerja. Kredit konsumtif merupakan jenis kredit perbankan yang permintaannya terus meningkat, dan juga mempunyai tingkat resiko yang besar apabila tidak dijalankan dengan prudent. Salah satu resiko yang ada yaitu permasalahan kredit macet atau non performing loan (NPL). Oleh karena itu, perlu analisis mendalam terhadap nasabah dalam perjanjian kredit dengan memperhatikan ketentuan mengenai prinsip kehati-hatian bank.

\section{Perumusan Masalah}

Berdasarkan berdasarkan uraian latar belakang tersebut, maka yang bahas dalam tugas akhir ini yaitu Bagaiman pelaksanaan prinsip kehati-hatian dalam pemberian kredit konsumtif pada Bank Nagari Cabang Siteba?

\section{Tujuan Penelitian}

Untuk mengetahui bagaiamanakah pelaksanaan Prinsip Kehati-hatian terkait pemberian Kredit konsumtif pada Bank Nagari Cabang Siteba.

\section{Metode Pengumpulan Data}

Penelitian yang dilakukan dengan membaca beberapa buku ilmiah dan tulisantulisan yang berkaitan dengan pembahasan yang dilakukan dan peninjauan langsung objek peneliti untuk untuk mendapatkan data primer. 


\section{METODE ANALISIS DATA}

Data yang diperoleh dari penelitian kepustakaan maupun dilokasi penelitian yaitu pada Bank Nagari Cabang Siteba khususnya yang berkaitan dengan prinsip kehati-hatian bank dalam pemberian kredit konsumtif dianalisa dengan menggunakan pendekatan kualitatif. Pendekatan kualitatif digunakan untuk menghasilkan data deskriptif.

\section{LANDASAN TEORI}

\section{Pengertian Bank}

Menurut Undang-Undang RI Nomor 10 tahun 1998 atas perubahan UU 7 Tahun 1992 pasal 1 ayat (2) tentang perbankan, yang dimaksud dengan bank adalah badan usaha yang menghimpun dana dari masyarakat dalam bentuk simpanan dan menyalurkannya kepada masyarakat dalam kredit dan bentuk-bentuk lainnya dalam rangka meningkatkan taraf hidup orang banyak.

\section{Pengertian Kredit}

Dalam arti luas kredit diartikan sebagai kepercayaan, sedangkan menurut bahasa Romawi istilah kata dari kredit dikenal dengan "Credere" yang artinya percaya.

Irham fahmi mengemukakan kredit adalah penyediaan uang atau tagihan yang dapat dipersamakan dengan itu, berdasarkan tujuan atau kesepakatan pinjam meminjam antara bank dan pihak lain yang mewajibkan pihak peminjam (debitur) untuk melunasi utangnya setelah jangka waktu tertentu dengan jumlah bunga, imbalan atau pembagian hasil keuntungan.

Dalam Undang-undang Perbankan No.10 tahun 1998 pasal 1 butir 11 kredit adalah penyediaan uang atau tagihan yang dapat dipersamakan dengan itu, berdasarkan persetujuan atau kesepakatan pinjam meminjam antara bank dengan pihak lain yang mewajibkan pihak peminjam melunasi hutangnya setelah jangka waktu tertentu dengan pemberian bunga.

\section{Unsur Kredit}

Revai veithzal menyebutkan unsur kredit sebagai berikut :

a. Adanya dua pihak

b. Adanya kepercayaan

c. Adanya persetujuan

d. Adanya penyerahan barang, jasa atau uang

e. Adanya unsur waktu

f. Adanya unsur resiko

Menurut Irham Fahmi dalam buku Manajemen perkreditan, bahwa unsur kredit sebagai berikut :

a. Kepercayaan

b. Tenggang waktu

c. Degree of risk

d. Prestasi

e. Adanya kreditur

f. Adanya debitur

\section{Jenis kredit}

Jenis kredit dilihat dari segi tujuan

a. Kredit produktif

b. Kredit konsumtif

c. Kredit perdagangan

Jenis kredit dilihat dari jangka waktu

a. Kredit jangka pendek 

b. Kredit jangka menengah
c. Kredit jangka panjang Jenis kredit menurut jaminan
a. Kredit tanpa jaminan
b. Kredit dengan jaminan

\section{Perjanjian Kredit}

Menurut Hermansyah dalam buku hukum perbankan nasional indonesia, perjanjian kredit adalah suatu peristiwa dimana dua orang atau dua pihak saling berjanji untuk melakukan suatu hal atau suatu persetujuan yang dibuat oleh dua pihak atau lebih, masingmasing bersepakat akan menaati apa yang tersebut dalam persetujuan itu.

Perjanjian kredit menurut Hukum Perdata Indonesia adalah salah satu dari bentuk perjanjian pinjam meminjam.

\section{Penggolongan Kredit}

Menurut ketentuan pasal 12 ayat (3) Peraturan Bank Indonesia No. 7/2/PBI/2005 tentang penilaian Kualiatas Aktiva Bank Umum, kualiatas kredit menjadi lima (5) kolektibilitas, yaitu :
a. Kredit lancar
b. Kredit dalam perhatian khusus
c. Kredit kurang lancar
d. Kredit diragukan
e. Kredit macet

\section{Prinsip kehati-hatian Dalam Pemberian Kredit}

Adapun prinsip-prinsip dalam pemberian kredit secara umum terdiri dari:
a. Prinsip kepercayaan
b. Prinsip kehati-hatian
c. Prinsip 5-C (charakter, capacity, capital, collateral, condition of economic)
d. Prinsip 4-P (purpose, payment, profitabilitas, protection)
e. Prinsip 3-R (returns, repayment, risk bearing ability)

\section{Pengawasan Terhadap Pelaksanaan Perjanjian Kredit}

Menurut Irham fahmi dalam buku manajemen perkreditan, ada dua bentuk pengawasan yang dilakukan oleh pihak perbankan dalam bidang pengawasan kredit yaitu :

a. Pengawasan dengan model preventif control

Pengawasan dengan model ini adalah dilakukan oleh pihak perbankan sebelum kredit tersebut dicairkan atau diberikan kepada debitur.

b. Pengawasan dengan model represif control

Pengawasan dengan model ini adalah dilakukan pada saat telah diberikan kepada debitur. Pengawasan disini diberikan dengan tujuan agar kreditur tersebut terbangun kedisiplinan yang kuat untuk melunasi setiap pinjamannya secara tepat waktu.

Peranan pengawasan bank adalah untuk memastikan apakah bank memiliki kebijakan, prosedur, dan pedoman penilaian kredit, serta menguji komistensi pelaksanaannya. 
ANALISA DAN PEMBAHASAN

1. Pelaksanaan Prinsip Kehati-hatian Dalam Pemberian Kredit Konsumtif Pada Bank Nagari Cabang Siteba

Proses pemberian kredit Konsumtif pada Bank Nagari Cabang Siteba dilaksanakan seperti dengan alur proses sebagai berikut:

\section{Gambar}

Proses Pemberian Kredit Konsumtif Pada Bank Nagari Cabang Siteba

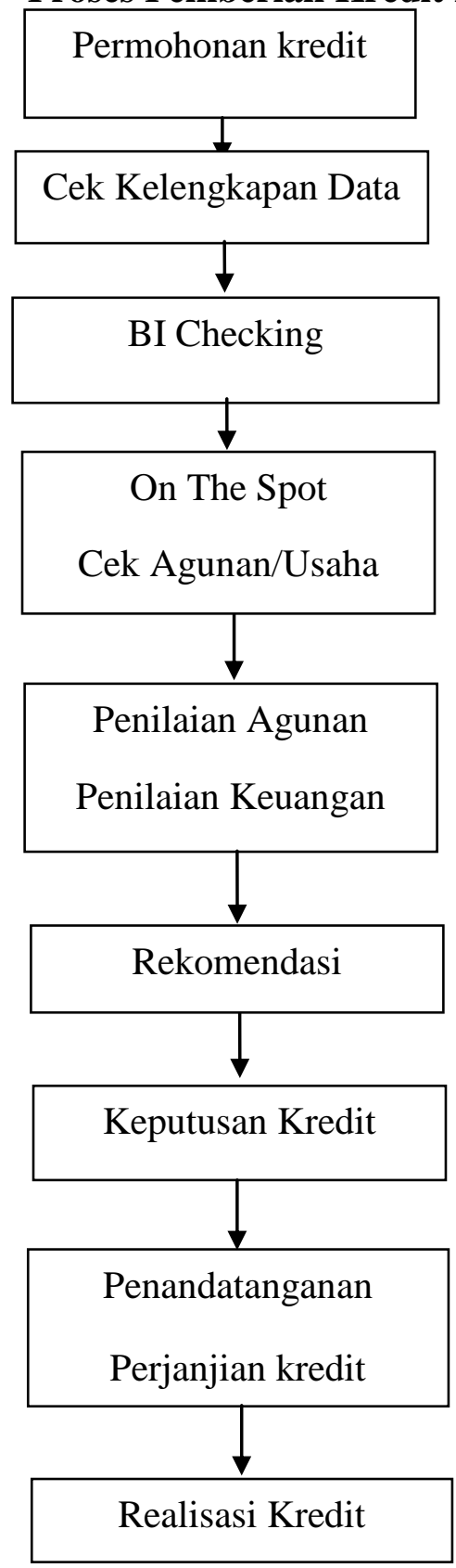

Sumber : Bank Nagari Cabang Siteba

Berdasarkan gambar diatas, pelaksanaan prinsip kehati-hatian dalam pemberian kredit konsumtif pada Bank Nagari Cabang Siteba dimulai dari penerimaan permohonan kredit yang diajukan oleh calon debitur. Permohonan kredit harus diajukan dalam bentuk tertulis dengan menggunakan format yang telah ditentukan oleh pihak Bank Nagari Cabang Siteba. Pada saat menerima permohonan dari pihak calon debitur, pihak bank memeriksa kelengkapan dan keaslian data-data calon debitur yang isinya tentang nama 
pemohon, tempat/tanggal lahir pemohon, NIP/NIK/Nomor kepegawaian pemohon, nomor Telepon/ HP pemohon, nama ibu kandung pemohon, nomor KTP/ SIM/ Pasport pemohon, nomor NPWP pemohon, pekerjaan/ jabatan pemohon, pangkat/ golongan pemohon, batas umur pensiun pemohon, nama kantor/ instansi pemohon, alamat kantor/ instansi pemohon, alamat rumah pemohoan, jumlah permohonan pinjaman, jangka waktu pinjaman, rencana penggunaan pinjaman, dan agunan yang diserahkan sebagai jaminan terhadap pinjaman. Adapun syarat kredit konsumtif yang harus dipenuhi dan dilampirkan oleh calon nasabah pada Bank Nagari Cabang Siteba sebagai berikut :

a) Surat Kuasa Memotong Gaji (SKMG)

b) Asli SK Calon Pegawai/SK Pengangkatan

c) Asli SK Pangkat Terakhir

d) Asli Kartu TASPEN/ASABRI

e) Daftar atau bukti gaji/penghasilan bulan terakhir

f) Fotocopy KTP

g) Fotocopy NPWP

h) Fotocopy berkala terakhir

i) Fotocopy buku tabungan di Bank Nagari

j) Bukti kepemilikan agunan bagi yang sesuai ketentuan berlaku harus menyerahkan agaunan tambahan

k) Surat pernyataan dan kuasa, bagi pemohon dengan jangka waktu khusus

Pemeriksaan yang dilakukan oleh pihak bank merupakan bentuk prinsip kehatihatian dalam pemberian kredit, Karena dari hasil pemeriksaan kelengkapan dan keaslian data-data tersebut pihak bank bisa menilai karakter calon debitur. Karakter merupakan salah satu dari prinsip kehati-hatian dalam pemberian kredit yaitu prinsip 5C, diantaranya character, capasity, capital, collateral, dan condition of economic.

Setelah pihak bank memeriksa kelengkapan dokumen tersebut. Hal yang dilakukan selanjutnya adalah memeriksa riwayat kredit pemohon pada bank lain dengan menggunakan SID (sistem informasi debitur) yang disebut dengan BI CHECKING (kalau ada). Pemeriksaan SID merupakan salah satu dari bentuk pelaksaan prinsip kehati-hatian bank dalam pemberian kredit, guna untuk meminimalisir kredit bermasalah. Pada saat pemeriksaan SID pihak bank dapat mengetahui Capacity calon debitur, karena dari hasil BI CHECKING terlihat data pinjaman nasabah pada bank lain, jadi pihak bank bisa menilai apakah calon debitur mampu untuk mengembalikan atau membayar angsuran jika kredit direalisasikan.

Setelah melakukan pemeriksaan BI CHECKING, pihak Bank Nagari Cabang Siteba melanjutkan proses pemberian kredit berdasarkan prinsip kehati-hatian yaitu melakukan on the spot agunan atau usaha debitur, tujuannya untuk mengetahui capital atau modal calon debitur. Dalam kredit konsumtif yang dimaksud dengan capital adalah jumlah gaji calon debitur, apakah jumlah gaji tersebut mencukupi untuk membayar angsuran dengan jumlah kredit yang diminta.

Setelah semuanya lancar pihak bank akan melakukan penilaian terhadap agunan yang dijaminkan oleh calon debitur. Dalam hal ini jaminan itu berupa SK asli calon debitur. Penilaian yang dilakukan oleh pihak bank adalah memeriksa keaslian SK yang dijaminkan, kemudian meminta foto copy berkala terakhir dari calon debitur. Pada saat 
penilaian agunan, pihak Bank Nagari Cabang Siteba menggunakan prinsip kehati-hatian dalam pemberian kredit konsumtif yaitu collateral. Apabila hasil dari analisis kredit yang dilakukan oleh devisi kredit sesuai dengan ketentuan Bank Nagari Cabang Siteba maka devisi kredit konsumtif akan mengajukan kepada pimpinan Cabang Siteba untuk merekomendasikan kredit tersebut.

Dari hasil rekomendasi kredit tersebut, pihak bank memberikan keputusan apakah permohonan diterima atau ditolak. Setelah kredit diterima, maka kedua belah pihak melakukan perjanjian kredit dengan menandatangani akad kredit, dan pihak bank akan mengikat agunan yang dijaminkan. Setelah itu kredit akan direalisasikan dengan persyaratan membuka rekening tabungan di Bank Nagari Cabang Siteba. Setelah semuanya selesai kredit akan dicairkan dan bisa diambil oleh pihak debitur atas realisasi pemberian kredit konsumtif. Setelah kredit direalisasikan dan dicairkan pihak bank masih menerapkan prinsip kehati-hatian dalam bentuk pengawasan kredit.

Jadi, pelaksanaan prinsip kehati-hatian dalam pemberian kredit konsumtif pada Bank Nagari Cabang Siteba tidak hanya dilakukan dari permohonan kredit sampai dengan realisasi kredit, tetapi juga dilaksanakan pada saat kredit telah dicairkan dengan melakukan pengawasan kredit yang tujuannya membangun kedisiplinan debitur untuk melunasi pinjamannya secara tepat waktu.

\section{Hambatan Yang Dihadapi Oleh Bank Nagari Cabang Siteba Dalam Pemberian Kredit Konsumtif}

Dalam pelaksanaan prinsip kehati-hatian terhadap pemberian kredit konsumtif juga menghadapi berbagai hambatan, yang terdiri dari hambatan internal dan hambatan eksternal yang mengakibatkan terjadinya kredit bermasalah. Hambatan internal merupakan hambatan yang timbul dari pihak bank, dalam hal ini kemampuan dari devisi kredit itu sendiri seperti kurang mahir dalam menganalisis laporan keuangan calon debitur, kurangnya pengecekan terhadap calon debitur, dan kurangnya pemahaman terhadap kebutuhan yang sebenarnya dari calon debitur. Semua itu karena setiap orang memiliki kemampuan dan karekter yang berbeda dalam menganalisa kredit. Sedangkan hambatan eksternal merupakan hambatan yang timbul dari luar seperti pihak nasabah, kondisi ekonomi, dan sebagainya.

Dalam pemberian kredit konsumtif Bank Nagari Cabang Siteba mengatakan bahwa telah melaksanakan dengan prinsip kehati-hatian. Jadi hambatan yang terjadi cenderung bersifat eksternal seperti kondisi ekonomi, persaingan, bencana alam, terjadinya PHK mendadak, penurunan omset usaha debitur, penggunaan kredit tidak sesuai rencana, dan terjadinya konflik keluarga.

Data kredit konsumtif berdasarkan kolektibilitas kredit pada Bank Nagari Cabang Siteba dapat dilihat dalam tabel dibawah ini: 
Tabel 1

Kolektibilitas Kredit Konsumtif pada tahun 2014-2016 (Dalam Ribuan Rupiah)

\begin{tabular}{|c|l|c|c|c|c|c|c|}
\hline No & $\begin{array}{l}\text { Kolektibilitas } \\
\text { kredit }\end{array}$ & $\mathbf{2 0 1 4}$ & $\mathbf{\%}$ & $\mathbf{2 0 1 5}$ & $\mathbf{\%}$ & $\mathbf{2 0 1 6}$ & $\mathbf{\%}$ \\
\hline 1 & Lancar & 192.821 & 21,79 & 216 & 0,102 & 258.874 & 97,66 \\
\hline 2 & $\begin{array}{l}\text { Dalam perhatian } \\
\text { khusus }\end{array}$ & 690.731 & 78,08 & 209.850 & 99,23 & 1.722 & 0,649 \\
\hline 3 & Kurang lancar & 24 & 0,002 & 240 & 0,113 & 302 & 0,113 \\
\hline 4 & Diragukan & 54 & 0,006 & 240 & 0,113 & 203 & 0,076 \\
\hline 5 & Macaet & 923 & 0,104 & 921 & 0,435 & 3.961 & 1,494 \\
\hline & Jumlah & 884.553 & 100 & 211.467 & 100 & 265.062 & \\
\hline & NPL & & 0,11 & & 0,66 & & 1,68 \\
\hline
\end{tabular}

Sumber : Bank Nagari Cabang Siteba

Berdasarkan tabel diatas terlihat bahwa kolektibilitas kredit yang tergolong kredit konsumtif (Kredit Cicilan Pegawai, Kredit Cicilan Pensiun, Kredit Kepemilikan Rumah/KPR, Kredit Multi Guna, dan KCC Anggota DPRD) pada Bank Nagari Cabang Siteba cenderung berfluktuasi. Dimana pada tahun 2014, memiliki jumlah kolektibilitas sebanyak Rp. 884.553 ternyata 21,79 \% atau Rp. 192.821 merupakan kredit lancar, dan kredit bermasalah (NPL) sebesar 0,11\% yang terdiri atas 78,08\% kredit dalam perhatian khusus, 0,002\% kredit kurang lancar, 0,006 \% kredit diragukan dan 0,104\% kredit macet. Pada tahun 2015 jumlah kolektibilitas sebesar Rp. 221.467, kredit lancar sebanyak 0,102 \% atau Rp. 216, dan jumlah kredit bermasalah (NPL) meningkat menjadi $0,66 \%$ yang terdiri atas 99,23\% kredit dalam perhatian khusus, 0,113\% kredit kurang lancar, $0,113 \%$ kredit diragukan dan 0,435 \% kredit macet. Kenaikan NPL disebabkan oleh keterlambatan debitur dalam membayar angsuran pokok dan bunga. Pada tahun 2016 jumlah kolektibilitas sebesar Rp. 265.062, kredit lancar sebanyak 97,66\% atau Rp.258.874, dan jumlah kredit bermasalah (NPL) sebesar 1,68\% yang terdiri atas 0,649 $\%$ kredit dalam perhatian khusus, 0,113 \% kredit kurang lancar, 0,076 \% kredit diragukan, 1,494\% kredit macet. Artinya pada tahun 2016 terjadi peningkatan NPL secara signifikan menjadi $1,68 \%$, terjadinya peningkatan tersebut dikarenakan beberapa faktor, kebanyakan dari faktor eksternal diantaranya seperti kondisi ekonomi, terjadi PHK mendadak ditempat kerja debitur, usaha debitur tutup, penurunan omset usaha debitur, penggunaan kredit tidak sesuai rencana, dan terjadinya konflik keluarga (bercerai). Sehingga mengakibatkan debitur tidak mampu untuk membayar angsuran pokok dan bunga pinjamannya.

3. Upaya Yang Dilakukan Oleh Bank Nagari Cabang Siteba Untuk Mengatasi Kredit Konsumtif Yang Bermasalah

Upaya yang dilakukan oleh Bank Nagari Cabang Siteba dalam mengatasi kredit konsumtif yang bermasalah sebagai berikut :

1. Melakukan peringatan dini

Yaitu pihak bank akan mengirim surat peringatan dini kepada debitur untuk segera membayar tungggakan kredit yang telah terjadi.

2. Melakukan penagihan langsung kepada pihak debitur

3. Melakukan Rescheduling (penjadwalan kembali) 
Yaitu upaya hukum untuk melakukan perubahan atas sebagian atau seluruh persyaratan perjanjian, yang berkenaan dengan jadwal pembayaran kembali / jangka waktu kredit termasuk tenggang, dan perubahan jumlah angsuran. Bila perlu dengan penambahan kredit.

4. Melakukan Reconditioning (persyaratan kembali)

Yaitu melakukan perubahan atas sebagian atau seluruh persyaratan perjanjian, yang tidak terbatas hanya kepada perubahan jadwal angsuran atau jangka waktu kredit saja. Tetapi perubahan kredit tersebut tanpa memberikan tambahan kredit.

5. Melakukan Restructuring (penataan kembali)

Yaitu upaya melakukan perubahan syarat-syarat perjanjian kredit yang terjadi pada debitur yang mengalami kesulitan untuk memenuhi kewajibannya. Yang dilakukan pihak bank antara lain, seperti penurunan suku bunga kredit, perpanjangan jangka waktu kredit, pengurangan tunggakan bunga kredit, pengurangan tunggakan pokok kredit, dan penambahan fasilitas kredit.

6. Pihak Bank Nagari Cabang Siteba juga telah menetapkan asuransi kredit, apabila terjadi kredit macet asuransi kredit juga membantu bank agar tidak dirugikan.

7. Pelelangan agunan yang dijaminkan.

Sebelum melakukan pelelangan agunan, pihak Bank Nagari Cabang Siteba telah melewati kebijakan dalam menangulangi kredit bermasalah seperti peringatan dini, penagihan langsung kepada pihak debitur, penjadwalan kembali (rescheduling), persyaratan kembali (reconditioning), penataan kembali (restructuring), dan mengansuransikan kredit, kemudian apabila nasabah debitur masih belum bisa membayar angsurannya pihak bank akan bertindak dengan melakukan pelelangan agunan yang dijaminkan. Pelelangan agunan merupakan upaya yang terakhir dalam menangulangi kredit macet.

\section{PENUTUP}

\section{Kesimpulan}

a. Pelaksanaan prinsip kehati-hatian dalam pemberian kredit konsumtif pada Bank Nagari Cabang Siteba dilakukan berdasarkan UU Perbankan, dan peraturan di Indonesia. Setiap tahapan yang dilakukan dalam proses pemberian kredit selalu dilaksanakan dengan menerapkan prinsip kehati-hatian, analisis yang cermat, pengawasan dan kebijakan yang menggunakan prinsip perbankan yang sehat.

b. Dalam pemberian kredit konsumtif pada Bank Nagari Cabang Siteba telah melaksanakan prinsip kehati-hatian. Jadi hambatan yang terjadi cenderung bersifat eksternal seperti kondisi ekonomi, persaingan, bencana alam, terjadinya PHK mendadak, penurunan omset usaha debitur, penggunaan kredit tidak sesuai rencana, dan terjadinya konflik keluarga.

c. Upaya yang dilakukan oleh Bank Nagari Cabang Siteba untuk mengatasi kredit konsumtif yang macet sebagai berikut :
a. Melakukan peringatan dini
b. Melakukan penagihan langsung
c. Melakukan rescheduling (penjadwalan kembali)
d. Melakukan reconditioning (persyaratan kembali) 
e. Melakukan restructuring (penataan kembali)

f. Menetapkan asuransi kredit

g. Pelelangan agunan yang dijaminkan

\section{Saran}

Dalam melakukan penyaluran kredit atau pemberian kredit konsumtif pihak bank agar lebih menekankan pada pengawasan kredit yang dilakukan pada saat kredit telah direalisasikan sampai pada kredit lunas. Tujuannya agar terhindar dari kredit bermasalah.

\section{DAFTAR PUSTAKA}

Alanshari, F., \& Marlius, D. (2018). Prosedur Pemberian Kredit KPR Pada PT. Bank Tabungan Negara (Persero) TBK Cabang Pembantu Bukittinggi. https://doi.org/10.31227/osf.io/rsfhc

Amelia, L., \& Marlius, D. (2018). Pengendalian Kredit Dalam Upaya Menciptakan Bank Yang Sehat Pada PT. Bank Pembangunan Daerah Sumatera Barat Cabang Utama Padang. https://doi.org/10.31227/osf.io/kpc64

Andriani, B., \& Susanto, R. (2019). Pengawasan Kredit PT. Bank Perkreditan Rakyat (BPR) Ophir Pasaman Barat. https://doi.org/10.31219/osf.io/aunvc

Baiya, \& Fernos, J. (2019). Analisis Faktor-Faktor Penyebab Kredit Macet Pada Bank Nagari Cabang Siteba. https://doi.org/10.31227/osf.io/4xuks

Darmawanto, \& Fernos, J. (2019). Prosedur Pemberian Kredit Pada Bank Nagari Cabang Sijunjung. https://doi.org/10.31227/osf.io/psqfy

Djoni S. Gazali, Rachmadi Usman. (2010). Hukum Perbankan, Jakarta: Sinar Grafika.

Dhumhana , Muhammad. (2000). Hukum Perbanakan Di Indonesia, cet.2 , Bandung : Citra Aditya Bakhti.

Fahmi , Irham . (2014). Mananjemen Perkreditan, Bandung : Alfabeta.

Firmansyah, A., \& Fernos, J. (2019). Analisis Kredit Bermasalah Dilihat Dari Standar Non Performing Loan (NPL) Pada PT. Bank Perkreditan Rakyat (BPR) Prima Mulia Anugrah Cabang Padang. https://doi.org/10.31227/osf.io/gcj94

Harun , M Hazniel . (1995). Aspek-Aspek Hukum Perdata Dalam Pemberian Kredit Perbankan, Jakarta : Ind-Hill Co.

Hermansyah . (2008). Hukum Perbankan Nasional Indonesia, Cet.4, Jakarta : Kencana.

Ibrahim , Johanes . (2004). Mengupas Tuntas Kredit Komersil dan Konsumtif, Bandung : Mandar Maju. 
Ikbal, M., \& Marlius, D. (2017). Pengaruh Jumlah Taksiran Dan Uang Pinjaman Terhadap Laba Bersih Pada PT. Pegadaian (UPC) Gurun Laweh. https://doi.org/10.31227/osf.io/uch4a

Orlando, A., \& Susanto, R. (2019). Mekanisme Pencairan Kredit Usaha Rakyat Pada PT. Bank Rakyat Indonesia Unit Lubuk Buaya. https://doi.org/10.31219/osf.io/zuv2y

Pratama, D., \& Fernos, J. (2019). Prosedur Pelaksanaan Kredit Usaha Rakyat (KUR) Pada PT. Bank Nagari Cabang Padang. https://doi.org/10.31227/osf.io/ag68j

Rachmadi Usman. (2001). Aspek-Aspek Hukum Perbankan di Indonesia, Jakarta: PT. Gramedia Pustaka Utama.

Revai Veithzal \& Andria Permata Veithzal . (1995). Credit Management Handbook, PT. Raja Grafindo Persaja.

Shanjaya, A. R., \& Marlius, D. (2017). Peranan Laporan Keuangan Dalam Kebijaksanaan Pemberian Kredit Kepada Calon Nasabah Pada PT. BPR Batang Kapas. https://doi.org/10.31227/osf.io/uxmg6

Siswanto Sutojo. (2008). Menangani Kredit Bermasalah: Konsep dan Kasus, Jakarta: PT. Damar Mulia Pustaka.

Undang-Undang Nomor 7 Tahun 1992 atas perubahan Undang-Undang Nomor 10 Tahun 1998 tentang Perbankan 